\title{
The stabilizing effects of genetic diversity on predator-prey
}

\section{dynamics [version 1; peer review: 2 approved, 1 approved with}

\section{reservations]}

\author{
Christopher F Steiner, Jordan Masse
}

Department of Biological Sciences, Wayne State University, Detroit, MI, 48202, USA

\author{
V1 First published: 12 Feb 2013, 2:43 \\ https://doi.org/10.12688/f1000research.2-43.v1 \\ Latest published: 12 Feb 2013, 2:43 \\ https://doi.org/10.12688/f1000research.2-43.v1
}

Open Peer Review

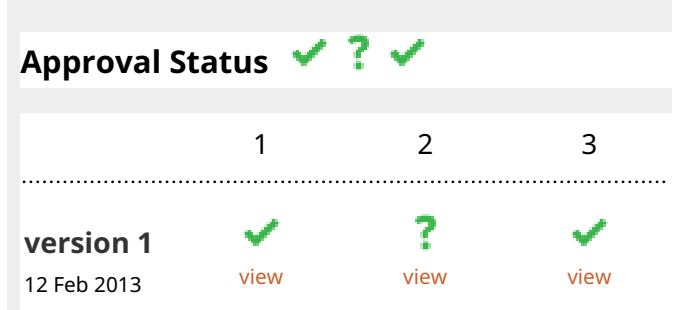

1. Eva Kisdi, University of Helsinki, Helsinki, Finland

2. Gregory Crutsinger, University of British Columbia, Vancouver, BC, Canada

3. Jordi Moya-Laraño, Estación Experimental de Zonas Áridas, Almería, Spain

Any reports and responses or comments on the article can be found at the end of the article. 
Corresponding author: Christopher F Steiner (csteiner@wayne.edu)

Competing interests: No relevant competing interests were disclosed.

Grant information: This research was supported by National Science Foundation grant DEB-0951495 to CFS.

The funders had no role in study design, data collection and analysis, decision to publish, or preparation of the manuscript.

Copyright: @ 2013 Steiner CF and Masse J. This is an open access article distributed under the terms of the Creative Commons

Attribution License, which permits unrestricted use, distribution, and reproduction in any medium, provided the original work is properly cited. Data associated with the article are available under the terms of the Creative Commons Zero "No rights reserved" data waiver (CC0 1.0 Public domain dedication).

How to cite this article: Steiner CF and Masse J. The stabilizing effects of genetic diversity on predator-prey dynamics [version 1; peer review: 2 approved, 1 approved with reservations] F1000Research 2013, 2:43 https://doi.org/10.12688/f1000research.2-43.v1

First published: 12 Feb 2013, 2:43 https://doi.org/10.12688/f1000research.2-43.v1 


\section{Introduction}

A large body of theoretical and empirical work has shown that the presence of variation among prey in their susceptibility to predation can have profound impacts on the structure and dynamics of predatorprey communities ${ }^{1-9}$. Prey heterogeneity can mediate trophic-level responses to enrichment and weaken top-down limitation of prey communities by facilitating numerical dominance by defended prey $^{2,4,7,10-12}$. Such shifts in dominance can have significant dynamic consequences, potentially reducing the propensity and severity of predator-prey oscillations and stabilizing community dynam$\operatorname{ics}^{1,3,5,9}$. While empirical research has largely focused on the consequences of interspecific variation in prey edibility, a growing body of experiments has begun to highlight the dynamic consequences of intraspecific trait variation. When prey populations exhibit phenotypic variation in their susceptibility to predators and show rapid adaptive responses to predation pressure, they can fundamentally alter the strength and dynamic consequences of their interactions with their consumers ${ }^{13-18}$.

The effects of prey heterogeneity on predator-prey dynamics has been extensively explored in the context of endogenously driven population cycles. Cycles are a common feature of simple, twospecies predator-prey models that incorporate nonlinear functional responses ${ }^{19-22}$. Such oscillatory dynamics become more probable and increase in amplitude with increasing prey carrying capacity ${ }^{20,21}$. Inclusion of prey heterogeneity in the form of species that are defended from predation can in theory stabilize predator-prey cycles. This readily occurs when prey species trade off their ability to compete for shared resources with their capacity to resist predation. In such instances, predators can facilitate the invasion and persistence of defended prey which, in turn, siphon resources from more edible species, reducing their carrying capacity. This can, in some cases, decrease the amplitude of predator-edible prey cycles or move systems from periodic to point attractors ${ }^{3,5,23}$. Predatormediated increases in the relative abundance of defended prey may also weaken top-down limitation of trophic-level abundance causing an increase in total prey abundance relative to prey community's lacking trait heterogeneity ${ }^{2,4,7,10-12}$.

While the abovementioned models were developed with the intent of understanding the dynamic consequences of heterogeneity among prey species, their general predictions may, under certain conditions, apply to heterogeneity that occurs within species. For instance, models of trophic structure that incorporate prey evolutionary dynamics show that heritable variation in defense against predators may allow prey populations to adaptively respond to predation pressure, shifting regulation of prey populations from top-down control to stronger bottom-up control ${ }^{13,24}$. Several models have also explored how adaptive responses in prey defense may impact predator-prey dynamics and stability ${ }^{14-16,18,24-26}$. These demonstrate the capacity for prey evolution to dramatically alter predatorprey dynamics but stabilization is not a generalizable prediction. While adaptive responses in prey defense may stabilize predator or prey populations under certain conditions ${ }^{14,15,24}$, evolution can also give rise to destabilization of predator-prey cycles and enhanced extinction probability ${ }^{14,16,17,25,26}$.
Only a handful of studies have attempted to address the dynamic consequences of intraspecific variability in prey edibility using direct manipulations in which prey evolution was either suppressed xor promoted ${ }^{16,17,27}$. Moreover, previous experiments have only considered phenotypes or species with fixed traits. For many organisms, ecological strategies may involve transitions between dynamic classes that vary in their susceptibility to predators, with variation among phenotypes consisting of variation in state transition rates or degree of invulnerability. This could apply to organisms that change behavioral/physiological states or who move in and out of spatial refuges. It could also occur with colony-forming organisms in which colonies of increasing size are more resistant to predators. Prior work has shown that such prey strategies can stabilize predator-prey cycles ${ }^{1}$. However, this has not been examined within an evolutionary context.

We tested this experimentally using a laboratory-based aquatic system composed of the zooplankton-predator Brachionus calyciflorus and the algal-prey Synura petersenii, in which the potential for prey evolution was either enhanced or reduced through direct manipulations of initial prey genetic diversity. Our study differed from prior work in its use of an algal-prey species that can transition between a vulnerable and predator-resistant class. Synura petersenii is a common freshwater flagellate that may transition between two states: either free-living cells (which are more susceptible to zooplankton predators) or as swimming colonies (which are less susceptible to zooplankton feeding due to their larger size). Reproduction can occur in either the free-living state or in the colony state through binary fission. The strains of $S$. petersenii used in our study exhibit heritable variation in their propensity to form colonies and their degree of vulnerability when in the colony state due to variation in colony size (Figure 1). Cellular aggregation and colony formation are viewed as key steps in the evolution of multicellularity ${ }^{28-30}$. Thus, our work also permits exploration of the selective forces that may favor colonial strategies. We show that the initial presence of trait heterogeneity among prey can reduce top-down limitation of prey and alter predator-prey dynamics by reducing temporal variation in total prey abundance. This stabilization is associated with an increase in the size of colonies and the relative abundance of cells found in colonies.

\section{Methods}

Our experimental system consisted of a single species of zooplankton as a predator, the rotifer Brachionus calyciflorus, and a single species of phytoplankton as the prey, the colony-forming flagellate Synura petersenii. Hereafter we refer to both species by genus. Brachionus cultures were obtained from Florida Aqua Farms (Dade City, FL, USA). Five strains of Synura were used in the experiment, four of which (LB239, LB2403, LB2405, LB2406) were obtained from UTEX (Austin, TX, USA) and one (CBS) from Carolina Biological Supply (Burlington, NC, USA). Synura stock cultures were initiated with a single cell isolated from serial dilutions in sterile medium to ensure that all stocks were initially isogenic. All five Synura strains produced populations composed of a mix of single cells and colonies when under semi-continuous culture conditions. However, short-term trait assays revealed significant genetic 
A

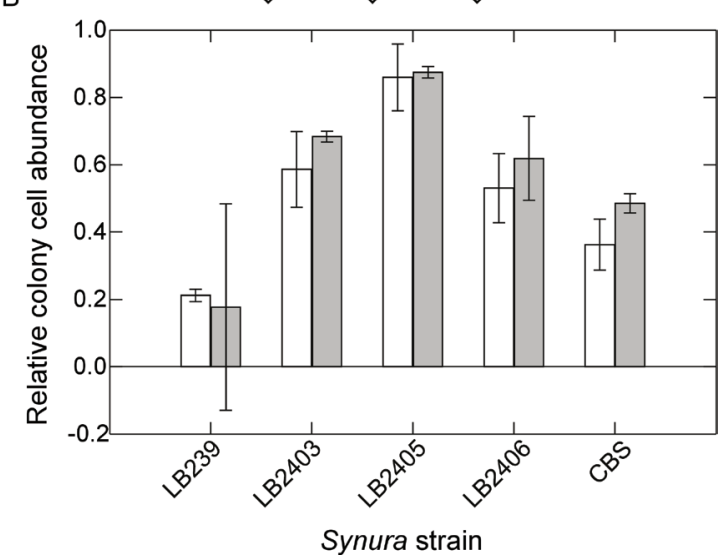

C

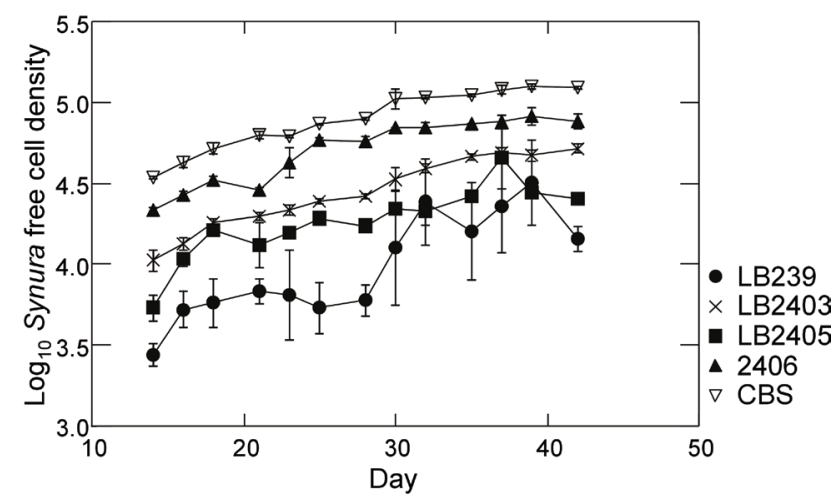

D

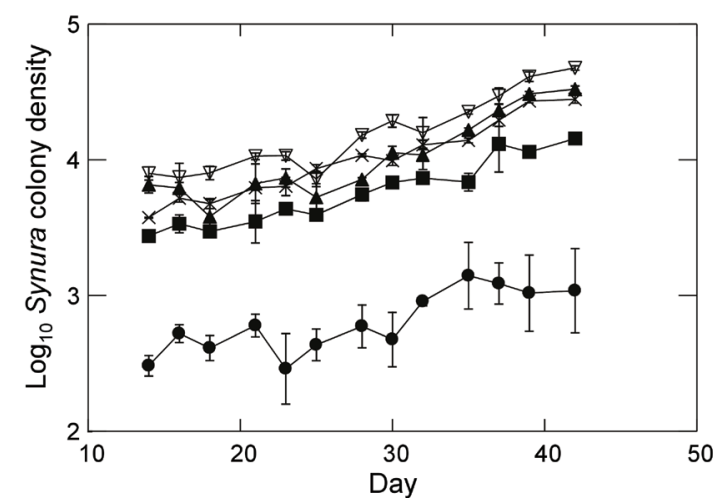

Figure 1. Results of short-term assays examining trait variation among the five Synura strains used in the experiment. Source cultures were maintained under common garden conditions using the same environmental conditions as the main experiment. Individuals of each Synura strain were isolated from one week old cultures and used to establish three replicate monocultures at an initial total cell density of $1500 \mathrm{cells} / \mathrm{mL}$. Monocultures experienced the same environmental conditions (light, temperature and nutrient replacement) and sampling procedures as the main experiment. (A) Mean cells per colony of each strain estimated from samples taken on day 14 and day 42 of the assay (shown are means and 95\% confidence intervals). (B) Mean relative abundance of cells found in colonies estimated from samples taken on day 14 and day 42 of the assay (shown are means and 95\% confidence intervals). (C) Density of free-living cells over time for each strain. Shown are means (+/- S.E.); original units in numbers of individuals per $\mathrm{mL}$. (D) Density of colonies over time for each strain. Shown are means (+/- S.E.); original units in numbers of colonies per $\mathrm{mL}$.

variation among the strains in population densities, colony size (number of cells per colony), and the relative abundance of total cells found in colony form (Figure 1). Brachionus used in the experiment were isolated from a clonal culture grown on the CBS strain of Synura. This culture was initially stocked with a single Brachionus clone, minimizing genetic variation within our Brachionus populations and reducing the potential for coevolution between predator and prey. All stock cultures were maintained using the same environmental conditions as in the experiment.

All experimental materials were autoclave-sterilized prior to use. Experimental containers consisted of $500 \mathrm{~mL}$ flasks filled with $400 \mathrm{~mL}$ of COMBO medium ${ }^{31}$, capped with aluminum foil and housed in a single environmental chamber at $20^{\circ} \mathrm{C}$ under 24 hour light. The containers were randomly ordered and rotated in the chamber following each sampling event. We used a factorial design in which predator presence/absence was crossed with a manipulation of initial genetic diversity (a low genetic diversity treatment composed of each Synura strain in monoculture or a high genetic diversity treatment composed of all five strains together). The treatments with Brachionus present were replicated four times; treatments without Brachionus were replicated three times. At the initiation of the experiment, flasks were first inoculated with their respective Synura strains from stock cultures. The high genetic diversity treatment received 20 cells $/ \mathrm{mL}$ of each of the five strains while the low diversity treatment received a single strain at 100 cells $/ \mathrm{mL}$. Thus, total Synura density added was kept constant at 100 cells $/ \mathrm{mL}$ across treatments. While the five strains were added at lower initial densities in the high genetic diversity treatment, each flask received a total of 8000 cells of each strain. Hence, the probability of losing a strain through demographic stochasticity and genetic drift at the initiation of the experiment was low. Synura populations were allowed to grow in the absence of predators for seven days at which time 10 Brachionus adults were added to each plus predator treatment. We refer to this as day 0 of the experiment. Brachionus populations were allowed to grow for 12 days (with periodic medium replacement) at which time sampling was initiated.

Sampling occurred every 2-3 days up to day 167 , the final day of the experiment. To sample the experiment, flasks were first gently 
swirled to homogenize their contents and $12.5 \%$ of the volume $(50 \mathrm{~mL})$ was poured into a sample bottle, which served as both a zooplankton and phytoplankton sample. Removed medium was replaced with sterile COMBO medium. Thus, the experiment was maintained under semi-continuous culture conditions. Brachionus was enumerated using a stereomicroscope while Synura was enumerated using a CASY particle counter (Innovatis AG, Germany). Maximum cell diameter of Synura in our cultures ranged between $6-10 \mu \mathrm{m}$ (mean $=7.9 \mu \mathrm{m})$; we found no significant differences among our strains in mean maximum diameter. Consequently, we programmed the CASY to perform total counts and counts of particles below $10.5 \mu \mathrm{m}$ mean diameter as an estimate of the density of free living cells. Colony densities were then calculated by subtracting single cell counts from totals. To measure the density of cells in colonies, we multiplied the colony counts by estimates of the mean number of cells per colony for each treatment replicate. Estimates of cells per colony were performed at four time points during the experiment: at the initiation of the experiment, on day 30, day 97 and at the end of the experiment. To obtain estimates, subsamples of phytoplankton from each replicate were preserved in acid Lugols solution and counts performed using a compound microscope. We counted cells/colony for up to 25 haphazardly chosen colonies per sample and averaged the values. Because we did not have mean colony size estimates for all dates, we time-averaged the estimates of cells/colony over days 30 to 167 to create conversion constants for each replicate prior to multiplying by the colony counts. This should have provided conservative estimates of treatments effects since treatments had not completely diverged by the day 30 sample. Total cell density was calculated by summing free-living cell densities with estimates of the density of cells found in colonies.

Brachionus populations in the low diversity treatment rapidly went extinct in all replicates of the LB239, LB2403, LB2405, and LB2406 strains. We consequently discontinued sampling of these monocultures and focused on the CBS strain for the low genetic diversity treatment. Brachionus populations exhibited an initial exponential growth phase followed by a population decline between days 0 and 40 before settling into more regular population oscillations. To remove the influence of initial transitory dynamics we analyzed data over days 51 to 167 . Significant linear trends over time in Synura and Brachionus densities were evident in several replicates (see Results). To remove the influence of temporal trends on measures of temporal variability, we first performed linear regressions of log transformed densities versus time for each replicate for both species. Mean absolute values of the regression residuals were then used as measures of temporal variability (an inverse measure of stability). Analyses of mean Brachionus and Synura densities were performed on $\log _{10}$ transformed values averaged over days 51 to 167 . To analyze changes in the degree of colony formation, we examined colony densities and the relative abundance of cells found in colonies (equal to the density of cells in colonies divided by total cell density). Response variables were analyzed using ANOVA. Because replication was not equal among replicates, we used type III sums of squares and max t-tests for post hoc comparisons, which are robust to unbalanced designs and non-normal data $^{32}$. All response variables met assumptions of normality using Lilliefor's test. Statistics were performed in R version $2.15^{33}$. Code for running max t-tests can be found $\mathrm{in}^{32}$.

\section{Results}

Brachionus populations persisted in all high genetic diversity treatments. However, populations of the zooplankton failed to establish in all low diversity replicates that were composed of the LB239, LB2403, LB2405, and LB2406 genotypes (sampling of these monocultures was discontinued). Brachionus also went extinct midexperiment in one low genetic diversity replicate containing the CBS strain; we have removed this replicate from all analyses. Figure 2 displays Brachionus dynamics for all replicates in the presence of either low initial genetic diversity (Figure 2A) or high initial genetic diversity (Figure 2B). When examining dynamics from day 51 to day 167, linear regressions revealed a significant positive trend in $\log$ Brachionus densities over time in one low genetic diversity replicate $(\mathrm{p}=0.02)$. Three of four high genetic diversity replicates exhibited significant negative trends in log Brachionus densities over time $(\mathrm{p}<0.05$, linear regression). Examining regression residuals, Synura genetic diversity had no effect on detrended temporal variability of Brachionus (Figure 3A; $\mathrm{p}=0.62$, ANOVA).

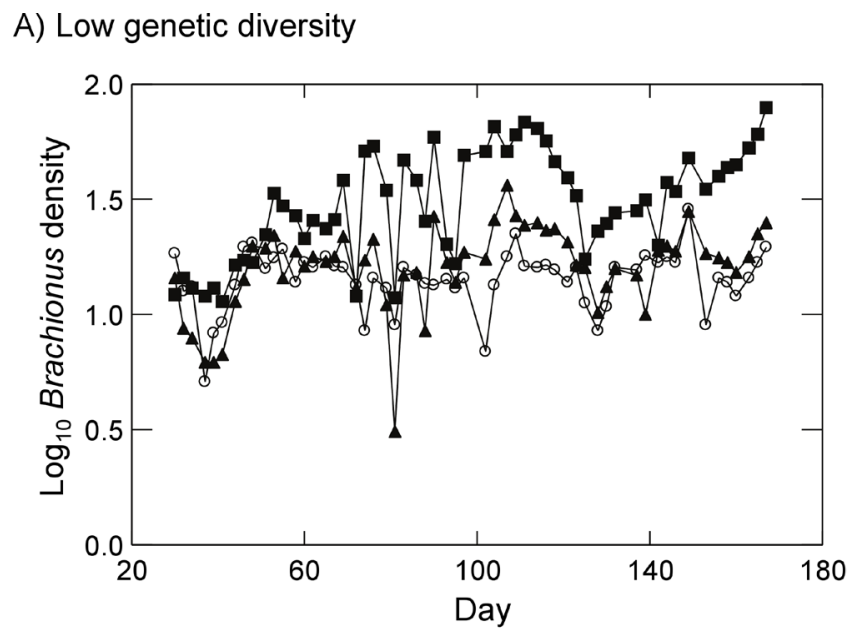

B) High genetic diversity

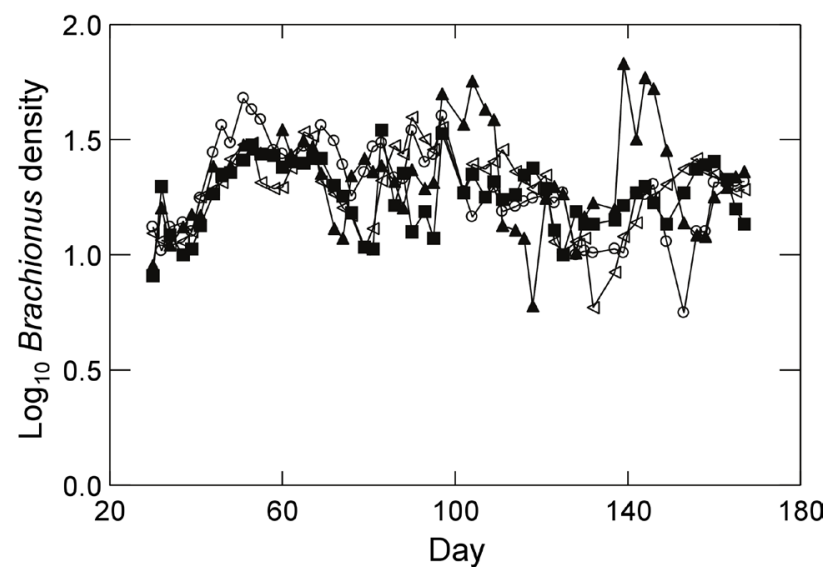

Figure 2. Brachionus dynamics in the presence of $(\mathbf{A})$ low initial prey genetic diversity (prey populations started with a single strain of Synura) or (B) high initial prey genetic diversity (prey population started with five strains of Synura). Dynamics for each replicate are shown separately (different symbols). Original units in numbers of individuals per $\mathrm{mL}$. 
A

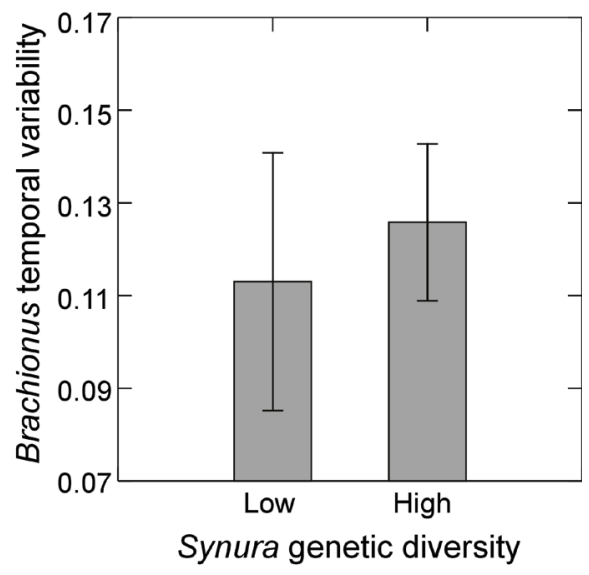

B

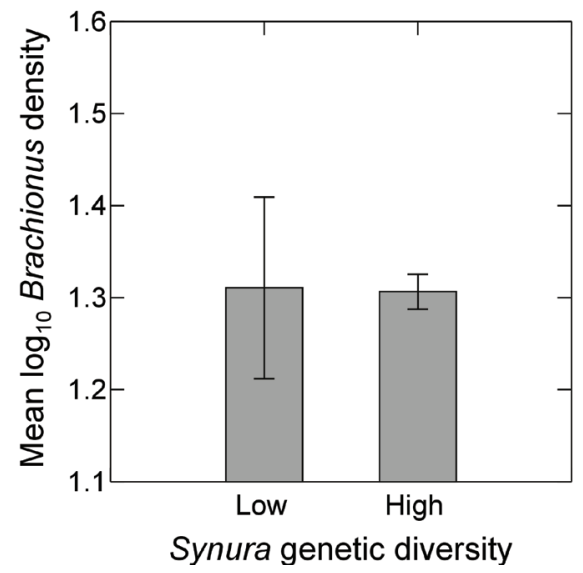

Figure 3. Effects of initial Synura genetic diversity (low versus high) on (A) detrended temporal variability of Brachionus populations (an inverse measure of stability), measured as mean residuals from linear regressions of log transformed Brachionus density versus time, and (B) Brachionus densities averaged over the course of the experiment. Both measures (A and $\mathbf{B}$ ) were based on dynamics over days 51 to 167. Shown are means (+/- S.E.). Original units in numbers of individuals per $\mathrm{mL}$.

Time-averaged Brachionus densities also showed no responses to initial Synura genetic diversity (Figure 3B; $\mathrm{p}=0.93$, ANOVA).

Synura dynamics for all treatments and replicates are shown in Figure 4. Examining dynamics from day 51 to day 167, log Synura densities in the low genetic diversity treatment and in the presence of Brachionus showed no significant trends with time across all three replicates (Figure 4A; all $\mathrm{p}<0.08$, linear regressions). By contrast, in the absence of Brachionus, Synura densities in the low genetic diversity treatments showed significant positive trends with time in all replicates (Figure 4A; all $\mathrm{p}<0.001$, linear regressions). Turning to Synura dynamics in the high genetic diversity treatments, all replicates exhibited significant positive increases over time in both the presence and absence of Brachionus (Figure 4B; all $\mathrm{p}<0.019$, linear regressions).
A) Low genetic diversity

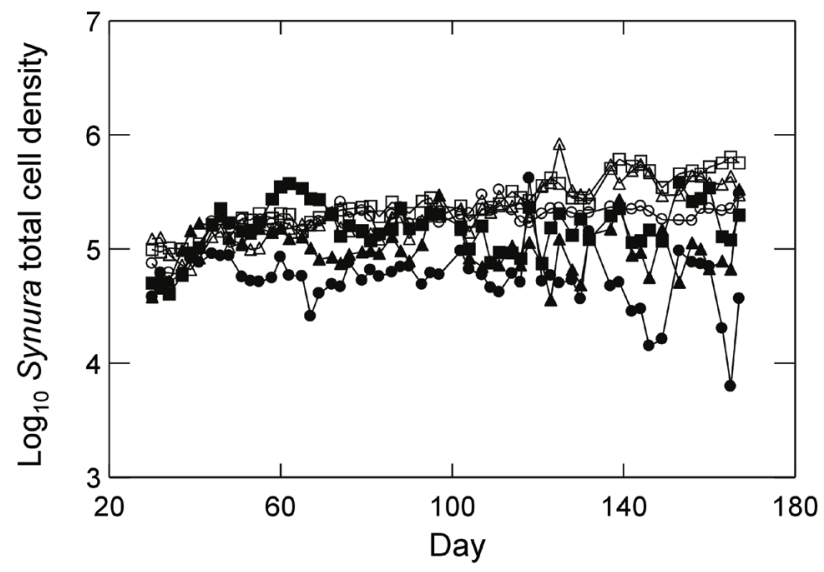

B) High genetic diversity

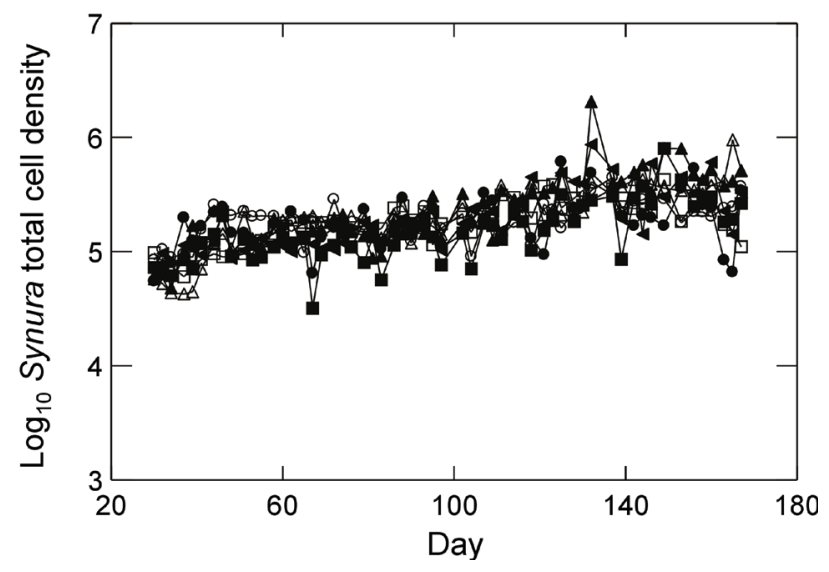

Figure 4. Synura dynamics in presence of Brachionus (closed symbols) or absence of Brachionus (open symbols) for (A) populations with low initial Synura genetic diversity or (B) populations with high initial Synura genetic diversity. Dynamics for each replicate are shown separately (different symbols). Original units in numbers of individuals per $\mathrm{mL}$.

Examining temporal variability of Synura total cell densities, a significant interaction between Brachionus presence/absence and initial genetic diversity was detected (Figure $5 \mathrm{~A} ; \mathrm{F}_{19}=26.9, \mathrm{p}<0.001$, ANOVA). Effects of genetic diversity on Synura stability were only strongly evident in the presence of Brachionus, significantly decreasing temporal variability in the high genetic diversity treatment relative to low genetic diversity (Figure $5 \mathrm{~A} ; \mathrm{p}=0.02$, max t-test). In contrast, no effects of initial genetic diversity were detected in the absence of Brachionus (Figure 5A; p=0.14, max t-test). We performed additional analyses of temporal variability of free-living cells and colony cell abundances to examine how these components contributed to variability in total cell density. Measures were detrended using linear regressions in the same manner as total cell densities. Temporal variability of free-living cells showed trends that mirrored variability of total cell abundances (Figure 6A). 
A

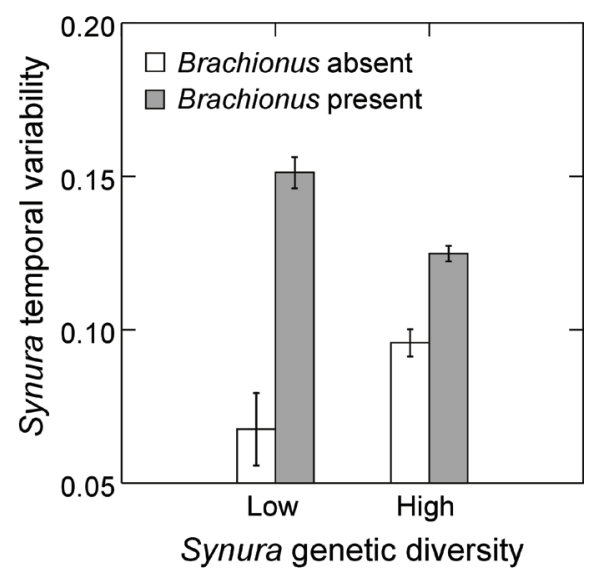

B

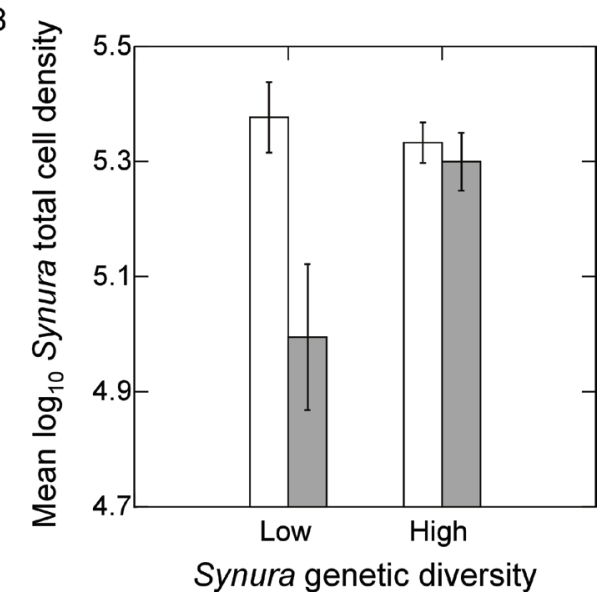

A

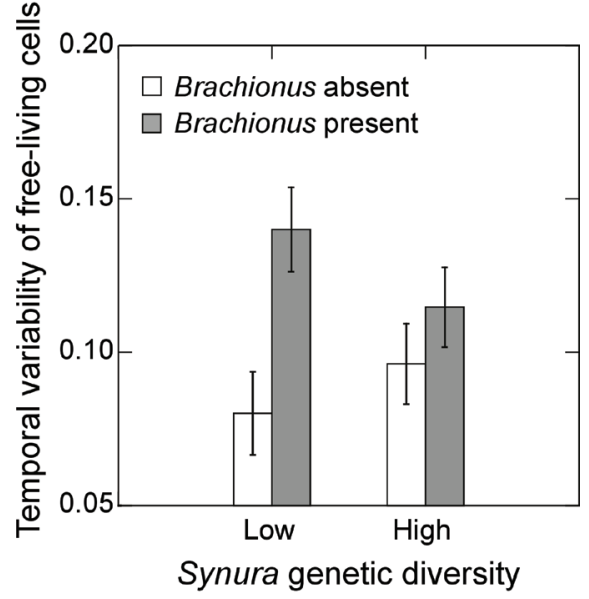

B

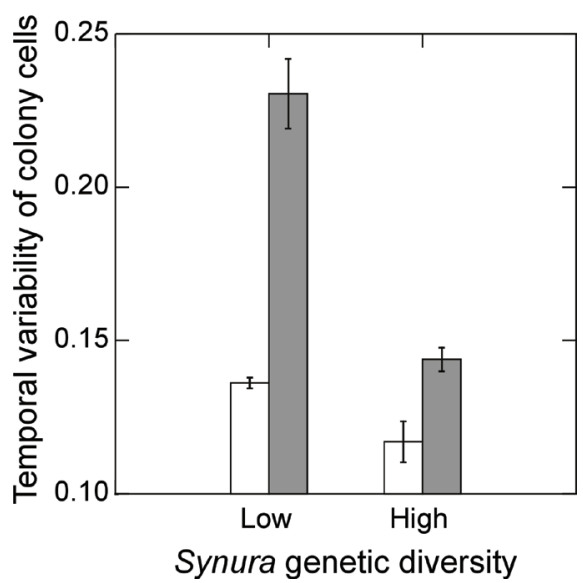

Figure 5. Effects of initial Synura genetic diversity (low versus high) and Brachionus presence/absence on (A) detrended temporal variability of Synura populations (based on total cell densities), measured as mean residuals from linear regressions of log transformed Synura density versus time, and (B) Synura total cell densities averaged over the course of the experiment. Both measures (A and B) were based on dynamics over days 51 to 167. Shown are means (+/- S.E.). Original units in numbers of individuals per $\mathrm{mL}$.

However, effects of genetic diversity were not strong (main effect: $\mathrm{p}=0.65$, ANOVA; interaction: $\mathrm{p}=0.10$, ANOVA) whereas Brachionus significantly increased temporal variability of free-living cells (Figure 6A; $\mathrm{F}_{1,9}=11.2, \mathrm{p}=0.01$, ANOVA). Genetic diversity and Brachionus presence/absence interactively affected temporal variability of colony cell abundances (Figure 6B; $\mathrm{F}_{1,9}=39.1, \mathrm{p}<0.001$, ANOVA). Genetic diversity reduced temporal variability in the presence $(\mathrm{p}<0.001$, max t-test) and absence of Brachionus $(\mathrm{p}=0.053$, max t-test), but effects were stronger when Brachionus was present (Figure 6B).

Effects of Brachionus presence/absence on total Synura cell densities also appeared to be dependent on initial genetic diversity (Figure 4A versus 4B). Analyzing time-averaged densities, a significant interaction was detected (Figure 5B; $\mathrm{F}_{1,9}=5.5, \mathrm{p}<0.043$, ANOVA). While Brachionus presence/absence had no effects on mean cell densities in the high genetic diversity treatment (Figure 5B;
Figure 6. Effects of initial Synura genetic diversity (low versus high) and Brachionus presence/absence (A) detrended temporal variability of free-living cells of Synura, measured as mean residuals from linear regressions of log transformed free cell densities versus time, and (B) detrended temporal variability of colony cells of Synura, measured as mean residuals from linear regressions of log transformed colony cell densities versus time. Shown are means $(+/-$ S.E.).

$\mathrm{p}=0.99$, max t-test), cell densities were significantly depressed in the presence of Brachionus in the low genetic diversity treatment (Figure 5B; $\mathrm{p}=0.03$, max t-test).

Presence of Brachionus reduced Synura colony density in both genetic diversity treatments (Figure 7A). When examining timeaveraged colony densities, a Brachionus effect was present (Figure 7B; $\mathrm{F}_{1,9}=49.7, \mathrm{p}<0.0001$, ANOVA) but no main effect of genetic diversity or interaction were detected ( $\mathrm{p}<0.37$, ANOVA). While the number of colonies was unaffected by initial genetic diversity, colony size (number of cells per colony) varied greatly between diversity treatments (Figure 8). When analyzing log transformed time-averages, a significant interaction between genetic diversity and Brachionus presence/absence on colony size was detected (Figure 8; $\mathrm{F}_{1,9}=68.9$, $\mathrm{p}<0.0001$, ANOVA). Colony size in the high genetic diversity treatment and in the presence of Brachionus was greater compared to all other treatment combinations (all $\mathrm{p}<0.001$, max t-test). Colony 


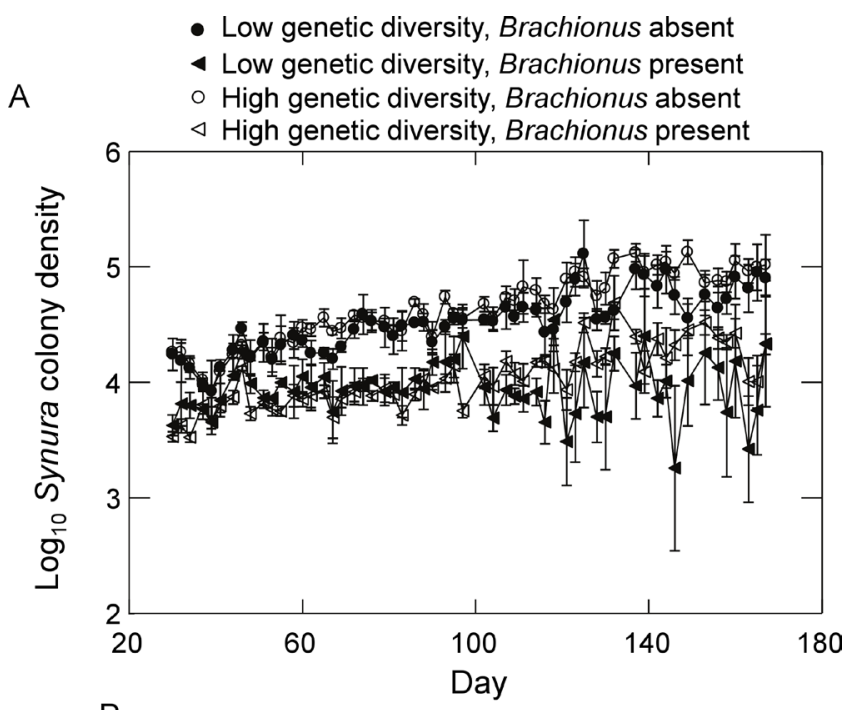

B

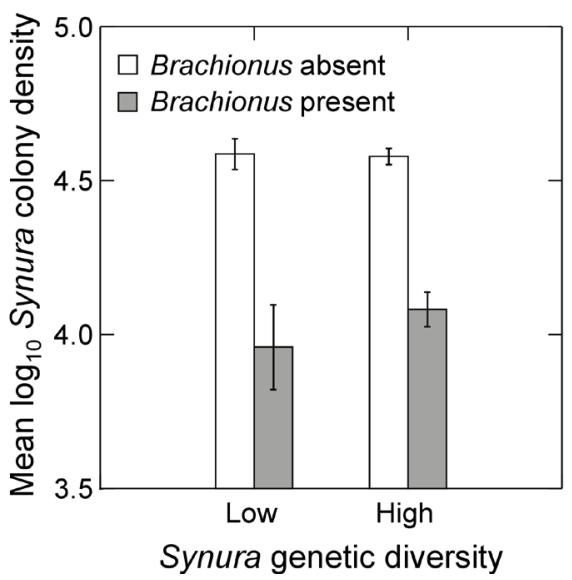

Figure 7. Effects of initial Synura genetic diversity (low versus high) and Brachionus presence/absence on (A) Synura colony densities over time (shown are means across replicates, +/-S.E.), and (B) Synura colony densities averaged over days 51 to 167 (means, $+/$-S.E.). Original units in numbers of colonies per $\mathrm{mL}$.

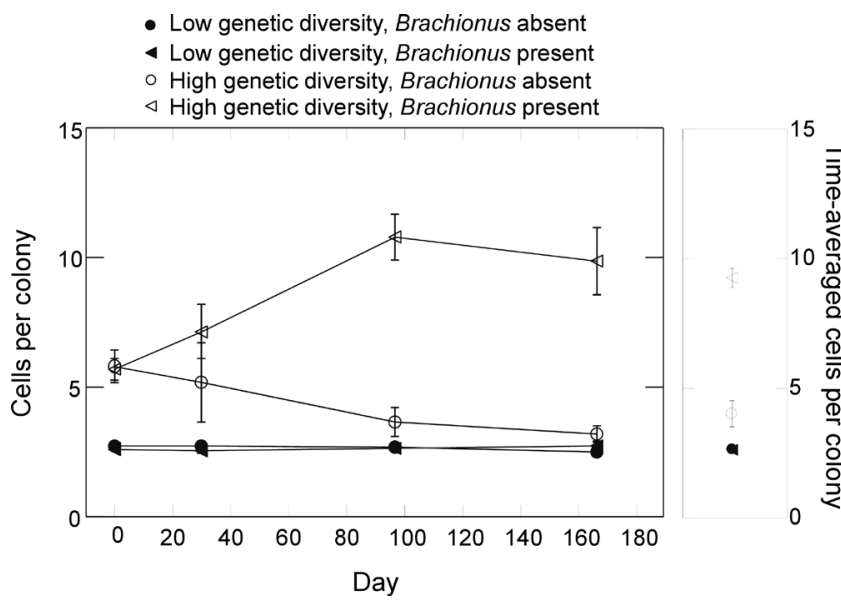

Figure 8. Effects of Synura genetic diversity and Brachionus presence/absence on the mean number of cells per Synura colony. The left panel displays dynamics over time and the right panel time-averaged values (averaged over days 30 to 167). Shown are means (+/- S.E.). size in the high genetic diversity treatment without Brachionus was also significantly greater than both low genetic diversity treatments ( $\mathrm{p}=0.03$, max t-test). In the low genetic diversity treatment, no effect of Brachionus presence/absence was detected ( $\mathrm{p}=0.99$, max t-test). Effects on colony size were also apparent when examining the relative number of cells in colonies, which increased greatly in the presence of Brachionus and high genetic diversity (Figure 9A). Analyzing time-averaged relative colony cell density produced a significant interaction between Brachionus presence/absence and initial Synura genetic diversity (Figure 9B; $\mathrm{F}_{1,9}=436.1$, $\mathrm{p}<0.0001$, ANOVA). There was no difference between low and high genetic diversity treatments when Brachionus was not present ( $\mathrm{p}=0.49$, max t-test) but a strong positive effect of Synura genetic diversity in the presence of Brachionus (Figure 9B; $\mathrm{p}<0.001$, max t-test).

\section{Brachionus synura timeseries}

2 Data Files

http://dx.doi.org/10.6084/m9.figshare.155786

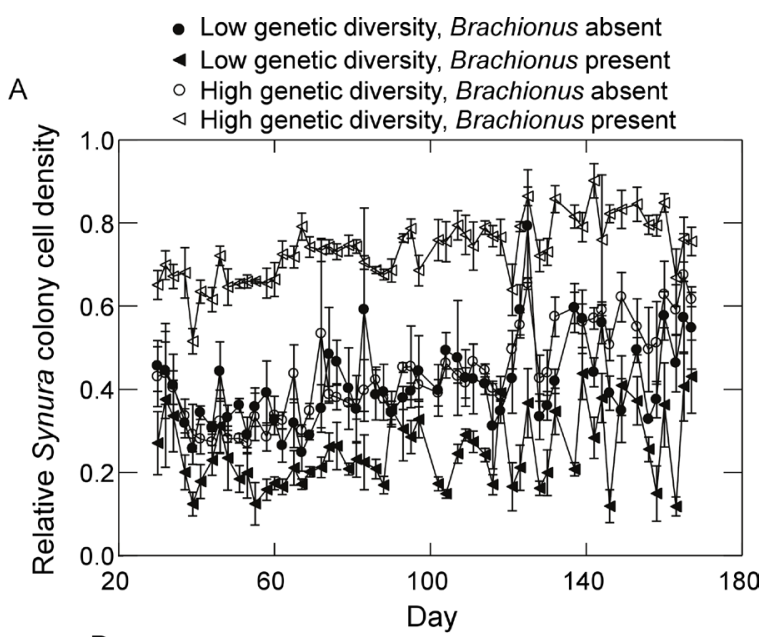

$B$

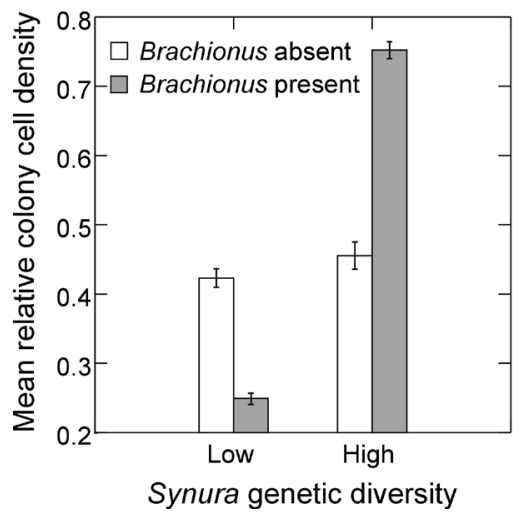

Figure 9. Effects of initial Synura genetic diversity (low versus high) and Brachionus presence/absence on $(\mathbf{A})$ the relative abundance of Synura cells found in colonies over time (shown are means across replicates, +/-S.E.), and (B) the relative abundance of Synura cells found in colonies averaged over days 51 to 167 (means, +/-S.E.). Relative colony cell density was calculated by dividing the number of cells found in colonies (per $\mathrm{mL}$ ) by the total cell density per $\mathrm{mL}$ (colony cells plus free-living cells). 


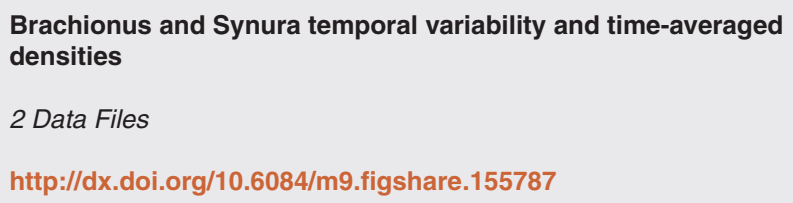

\section{Discussion}

We found clear evidence that the presence of intraspecific trait heterogeneity can positively impact the stability and abundance of prey populations when in the presence of predators. These effects were linked to increases in the degree of aggregation of prey individuals into colonies; diverse prey populations produced larger colonies and a greater relative abundance of cells found in colony form when predators were present. Our results bear many similarities to prior studies that have examined the dynamic consequences of interspecific variation in prey defense against predators. As outlined in our Introduction, several models have shown that the presence of weakly interacting prey can stabilize dynamics by shunting resources away from more edible forms and subsequently reducing the amplitude of predator-edible prey oscillations $s^{3,5,23}$ - a prediction that has garnered some empirical support from studies that have manipulated prey species composition ${ }^{6,34,35}$ and clonal composition ${ }^{15}$. Our work further demonstrates that intraspecific variation can stabilize dynamics when prey persist in different dynamic classes that vary in predator resistance. The mechanisms that can give rise to vulnerable-invulnerable class structures within prey populations are diverse and include refuge use, inter-individual variation in behavioral or physiological states, and spatial variation in predation pressure $^{1}$. Thus, our general findings may have broader applicability beyond planktonic systems of colony-forming prey.

While stabilization is one potential outcome of enhanced prey diversity, several models have shown that the evolution of prey defense may also destabilize predator-prey dynamics, depending on assumptions of prey and predator traits ${ }^{15,17,25}$. For example, Hairston, Ellner and colleagues have examined the dynamic consequences of evolutionary responses among prey using models and an experimental system composed of Brachionus calyciflorus and unicellular green algae as prey ${ }^{14-17}$. They have shown both theoretically and experimentally that rapid prey adaption in prey edibility can have significant effects on predator-prey dynamics, though effects are not always stabilizing and dependent on the degree of prey phenotypic variation present and the strength of trade-offs among phenotypes in anti-predator strategies and competitive ability for shared resources. When predator-resistance is effective but costly to defended phenotypes, rapid prey adaptation can induce large predatorprey oscillations and destabilization ${ }^{14,16,18}$. In contrast, when defense against predators is effective but costs in competitive ability are low, prey adaptation can result in cryptic prey cycles in which predators continue to oscillate and total prey abundance is stabilized as edible and predator-resistant phenotypes oscillate out of phase of each other ${ }^{15,18}$. The production of cryptic cycles via rapid prey adaptation shows a passing similarity to our results, in which high genetic diversity had no effects on predator stability but led to stabilization of total Synura abundance in the presence of Brachionus. Because our sampling intervals were uneven, spanning 2 or 3 days, we could not examine covariation between free-living cells and colony cell abundances using traditional cross-correlation analysis. However, visual examination of detrended abundances of freeliving Synura cells and colony cells over time revealed no strong support for asynchronous oscillations between the two groups (Figure 10). Dynamics were instead highly synchronous; significant positive correlations were detected for all replicates (Figure 10).

The absence of cryptic cycles in our experiment is perhaps not surprising as the life history of our prey species is quite different from that assumed in prior models in which different genotypes have fixed traits. As described above, Synura can persist in two phenotypic states: susceptible free-living cells or a more predator-resistant colonial stage. Cells can transition between states via cellular aggregation and colony disassembly or subsets of the population can remain within states since both free living cells and colonies can reproduce - the latter through binary fission ${ }^{36}$. The prey life history in our experimental system is similar to the prey strategy presented in model 1 of $^{1}$, in which a single prey species transitions between a vulnerable and invulnerable class, both of which may reproduce. Their model, in addition to several variants, shows that class transitions can reduce top-down control of prey and stabilize dynamics by moving predator-prey cycles to point attractors. However ${ }^{1}$, only focused on a two species system in the absence of prey evolution. Exploration of the eco-evolutionary dynamics of multi-class prey systems may prove fruitful as it seems plausible that many natural prey populations could persist in multiple dynamic classes that vary in their ecological traits.

Our work also produced results that were similar to prior investigations of the consequences of prey heterogeneity on top-down versus bottom-up control of trophic-level production ${ }^{2,4,7,10-12,37}$. These studies have all provided strong empirical evidence that predators can facilitate numerical dominance of defended prey species or phenotypes, reducing predator limitation of total prey production. Similarly, we found that presence of predators selected for dominance by large colony phenotypes with reduced susceptibility to predation pressure. This resulted in a significant increase in mean prey abundance when compared to populations that were initially composed of a single, susceptible phenotype. Hence, prey evolution has the capacity to alter trophic structure and the partitioning of production among trophic levels.

As with any experiment, there are caveats and limitations in our study that deserve mention. First, it is important to note that our contrast between low and high prey genetic diversity was performed with a single genotype (CBS) for the low diversity treatment. 
A) Low genetic diversity
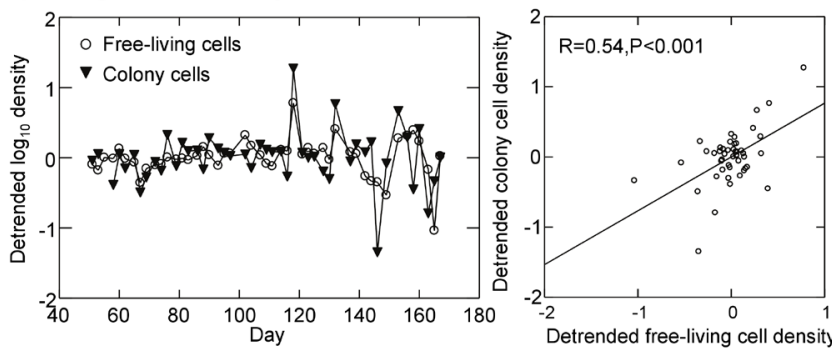

B) Low genetic diversity
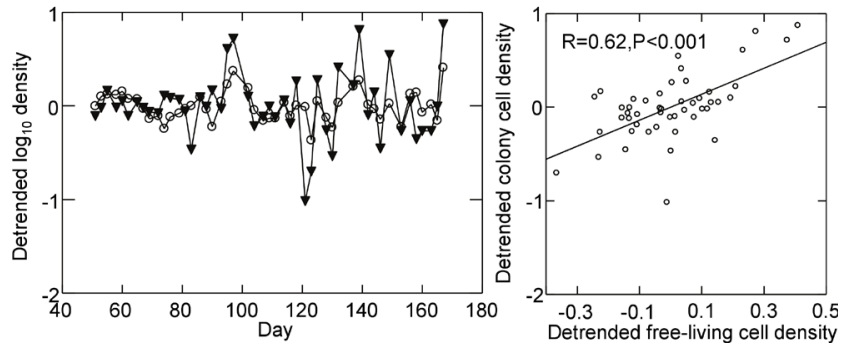

C) Low genetic diversity
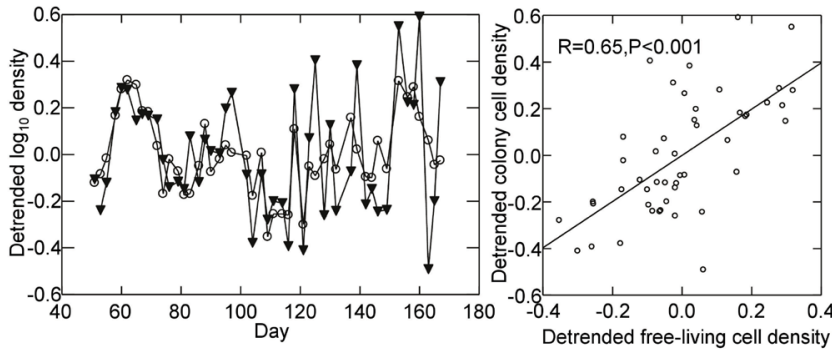

G) High genetic diversity

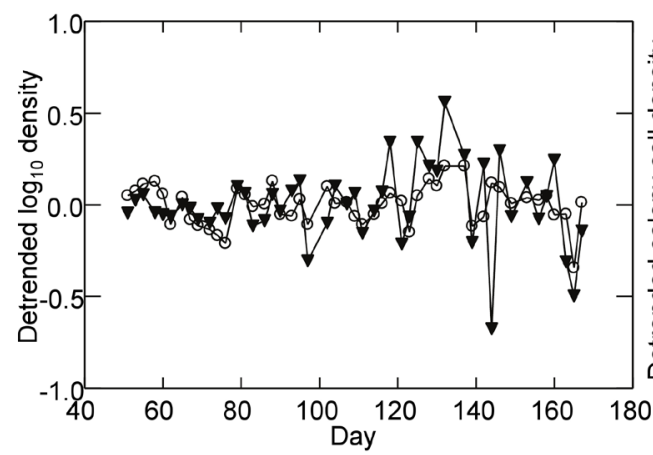

D) High genetic diversity
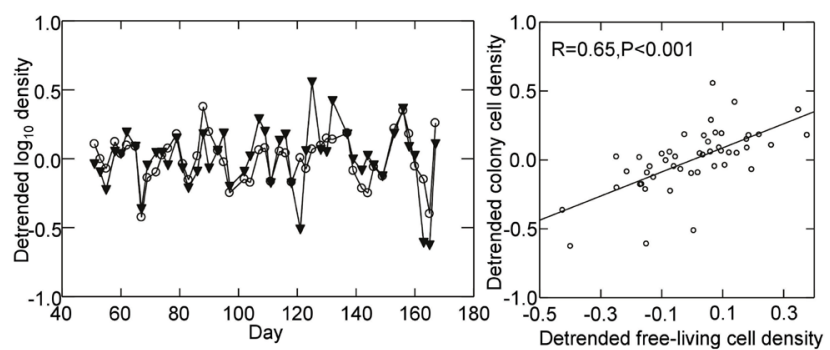

E) High genetic diversity
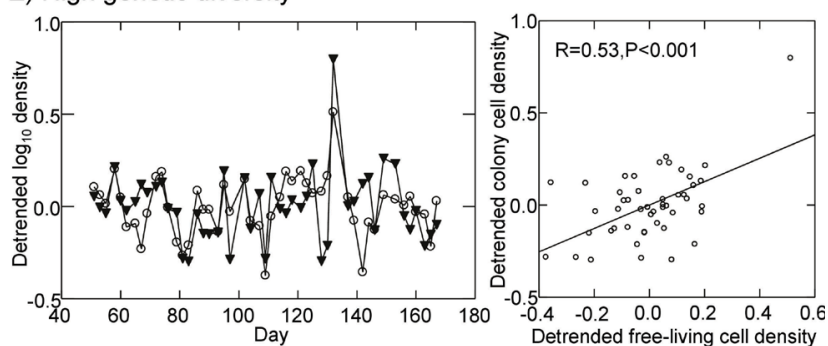

F) High genetic diversity
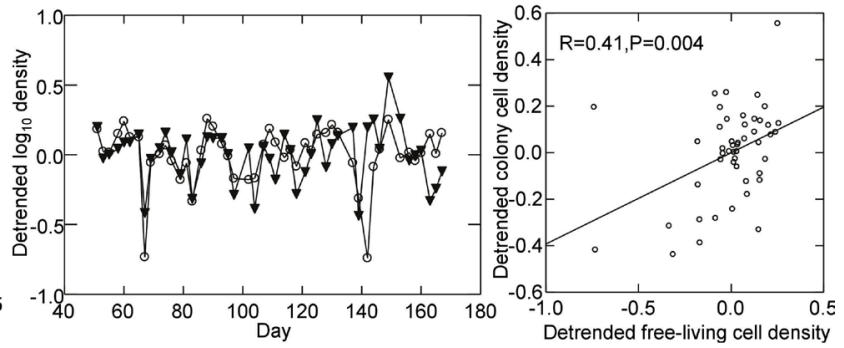

Detrended free-living cell density

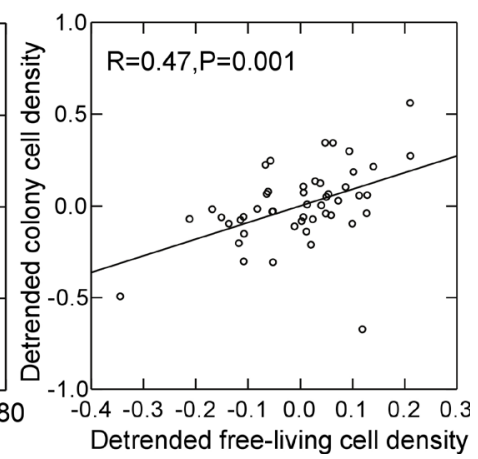

Figure 10. Detrended dynamics of Synura free-living cells and colony cell abundances in the presence of Brachionus (left panels) for all three replicates of the low genetic diversity treatment $(\mathbf{A}-\mathbf{C})$ and all four replicates of the high genetic diversity treatment (D-G). Shown for each replicate in the right panel is the relationship between free-living cell and colony cell abundances and Pearson correlation statistics (the line is the linear regression fit). Detrended abundances are the residuals from linear regressions of either log free-living cell densities or log colony cell densities versus time. 
This is an approach that has been used in prior experiments in which dynamics in the presence of a highly edible prey phenotype are contrasted with dynamics in which the edible prey has been supplemented with additional phenotypes that vary in their susceptibility to predators ${ }^{2,7,9,16}$. In the present case, this was done out of necessity since we observed that the CBS Synura strain was the only one capable of maintaining Brachionus populations at densities that were not prone to rapid extinction. This was likely due to the CBS strain's combination of high cell density, small colony size and low relative abundance of cells in colonies compared to the other strains (Figure 1). The only exception to this was strain LB239, which also had small colonies and a low relative abundance of cells in colony form. However, this strain also exhibited the lowest cell densities among the prey genotypes (Figure 1), which likely contributed to predator extinctions. If using extinction probability as a measure of predator stability, our results bolster our argument that prey genetic diversity enhances stability; in monocultures of Synura, Brachionus extinction probability was high for four out of five strains but low in the prey polyculture. Another limitation of our study is that we did not measure competitive abilities among our Synura strains. A central assumption of many of the abovementioned models is that prey exhibit trade-offs in their ability to resist predation and their competitive ability for shared resources ${ }^{3,11,13,14,23,26,38,39}$. Hence, investment in defensive traits - whether behavioral, chemical or morphological - comes at a cost to the organism in terms of its ability to acquire or convert limiting resources to growth and reproduction. While we did not measure competition between our Synura strains, it is conceivable that colony aggregation and increasing colony size could incur a fitness cost on individual cells by reducing exposed cell surface area and impairing the ability of individuals to acquire nutrient resources. Assuming a single limiting resource, models predict that phenotypes with high competitive ability should exclude less competitive, defended phenotypes at equilibrium and in the absence of predators. Results from our experiment were consistent with this prediction. In the absence of Brachionus, mean colony size and the relative abundance of Synura cells in colonies fell to low levels that were similar in magnitude to the low diversity treatment. This is indicative of a shift in dominance to phenotypes with lower investment in defense.

Cellular aggregation is viewed as an evolutionary stepping stone between unicellular and multicellular life forms ${ }^{28,30,40}$. A hurdle in achieving this initial transition is the fitness costs associated with colony formation such as reductions in competitive ability, reproductive rates or buoyancy. Our work supports the general idea that colony formation and large colony size provide a selective advantage in the presence of predators and a disadvantage when predators are absent and resource competition is strong. This finding complements previous studies that have shown similar effects of predators on colony formation in unicellular algae ${ }^{17,41}$ and supports the general hypothesis that a driver in the early evolution of multicellularity was the emergence of heterotrophic life forms and phagotrophy a transition point where the disadvantages of cellular aggregation began to be outweighed by the advantages of increasing size and predator escape ${ }^{29}$. Our study also adds to a growing body of experiments demonstrating the effects of rapid evolutionary change on the dynamics of consumer-resource interactions ${ }^{2,16,17,27,42}$ and the strength of top-down control of prey abundance ${ }^{2,37}$. How such effects translate to natural communities remains largely unresolved; the majority of prior experiments, including ours, have utilized highly simplified laboratory settings with a minimal number of interacting species. Moreover, the consequences of coevolutionary responses between predator and prey populations on ecological dynamics have not been deeply explored. Natural prey populations are of course exposed to multiple species of predators and embedded in prey communities with a large degree of interspecific variation in competitive ability and defense against predators. Understanding the dynamic consequences of evolution and coevolution within the context of complex communities remains a daunting challenge in ecology but an exciting avenue for future exploration.

\section{Author contributions}

CFS conceived the study, designed the experiment, analyzed the data and wrote the manuscript. CFS and JM carried out the experiment.

\section{Competing interests}

No relevant competing interests were disclosed.

\section{Grant information}

This research was supported by National Science Foundation grant DEB-0951495 to CFS.

The funders had no role in study design, data collection and analysis, decision to publish, or preparation of the manuscript.

\section{Acknowledgements}

We are grateful to Drew Stockwell, Laith Shaman, Monica Tadros, Michelle Nawal, and Mariela N-Tyler for lab assistance and Emily Grman for comments on the manuscript.
1. Abrams PA, Walters CJ: Invulnerable prey and the paradox of enrichment. Ecology. 1996; 77(4): 1125-1133.

Publisher Full Text

2. Bohannan JM, Lenski RE: Effect of prey heterogeneity on the response of a model food chain to resource enrichment. Am Nat. 1999; 153(1): 73-82. Publisher Full Tex
3. Kretzschmar M, Nisbet RM, McCauley E: A predator-prey model for zooplankton grazing on competing algal populations. Theor Popul Biol. 1993; 44(1): 32-66. Publisher Full Text

4. Leibold MA, Chase JM, Shurin JB, et al: Species turnover and the regulation of trophic structure. Annu Rev Ecol Syst. 1997; 28: 467-494. Publisher Full Text 
5. McCann K, Hastings A, Huxel GR: Weak trophic interactions and the balance of nature. Nature. 1998; 395(6704): 794-798.

Publisher Full Text

6. McCauley E, Nisbet RM, Murdoch WW, et al:: Large-amplitude cycles of Daphnia and its algal prey in enriched environments. Nature. 1999; 402(6762): 653-656. Publisher Full Text

7. Steiner CF: The effects of prey heterogeneity and consumer identity on the limitation of trophic-level biomass. Ecology. 2001; 82(9): 2495-2506. Publisher Full Text

8. Paine RT: Food web complexity and species diversity. Am Nat. 1966; 100(910): $65-75$

Publisher Full Text

9. Steiner CF, Klausmeier CA, Litchman E: Transient dynamics and the destabilizing effects of prey heterogeneity. Ecology. 2012; 93(3): 632-44. PubMed Abstract | Publisher Full Text

10. Chase JM, Leibold MA, Downing AL, et al.: The effects of productivity, herbivory, and plant species turnover in grassland food webs. Ecology. 2000; 81(9): 2485-2497.

Publisher Full Text

11. Leibold MA: Resource edibility and the effects of predators and productivity on the outcome of trophic interactions. Am Nat. 1989; 134(6): 922-949. Publisher Full Text

12. Steiner CF: Keystone predator effects and grazer control of planktonic primary production. Oikos. 2003; 101(3): 569-577. Publisher Full Text

13. Loeuille N, Loreau M: Nutrient enrichment and food chains: can evolution buffer top-down control? Theor Popul Biol. 2004; 65(3): 285-98.

PubMed Abstract | Publisher Full Text

14. Shertzer KW, Ellner SP, Fussmann GF, et al:: Predator-prey cycles in an aquatic microcosm: testing hypotheses of mechanism. J Anim Ecol. 2002; 71(5): 802-815.

Publisher Full Text

15. Yoshida T, Ellner SP, Jones LE, et al:: Cryptic population dynamics: rapid evolution masks trophic interactions. PLoS Biol. 2007; 5(9): e235. PubMed Abstract | Publisher Full Text | Free Full Text

16. Yoshida T, Jones LE, Ellner SP, et al.: Rapid evolution drives ecological dynamics in a predator-prey system. Nature. 2003; 424(6946): 303-6. PubMed Abstract | Publisher Full Text

17. Becks L, Ellner SP, Jones LE, et al.: Reduction of adaptive genetic diversity radically alters eco-evolutionary community dynamics. Ecol Lett. 2010; 13(8): 989-97.

PubMed Abstract | Publisher Full Text

18. Jones LE, Ellner SP: Effects of rapid prey evolution on predator-prey cycles. J Math Biol. 2007: 55(4): 541-73.

PubMed Abstract | Publisher Full Text

19. Fussmann GF, Ellner SP, Shertzer KW, et al.: Crossing the Hopf bifurcation in a live predator-prey system. Science. 2000; 290(5495): 1358-60. PubMed Abstract | Publisher Full Text

20. Gilpin ME, Rosenzweig ML: Enriched predator-prey systems: theoretical stability. Science. 1972; 177(4052): 902-4. PubMed Abstract | Publisher Full Text

21. Rosenzweig ML: Paradox of enrichment: destabilization of exploitation ecosystems in ecological time. Science. 1971; 171(3969): 385-7. PubMed Abstract | Publisher Full Text

22. May RM: Limit cycles in predator-prey communities. Science. 1972; 177(4052): 900-2.

PubMed Abstract | Publisher Full Text

23. Grover JP: Competition, herbivory, and enrichment: nutrient-based models for edible and inedible plants. Am Nat. 1995; 145(5): 746-774.

Publisher Full Text

24. Hochberg ME, Holt RD: Refuge evolution and the population dynamics of coupled host-parasitoid associations. Evol Ecol. 1995; 9(6): 633-661. Publisher Full Text

25. Abrams PA, Matsuda H: Prey adaptation as a cause of predator-prey cycles. Evolution. 1997; 51(6): 1742-1750.

Reference Source

26. Jones LE, Becks L, Ellner SP, et al.: Rapid contemporary evolution and clonal food web dynamics. Philos Trans R Soc Lond B Biol Sci. 2009; 364(1523): 1579-91. PubMed Abstract | Publisher Full Text | Free Full Text

27. Pimentel D, Nagel WP, Madden JL: Space-time structure of the environment and the survival of parasite-host systems. Am Nat. 1963; 97(894): 141-167. Publisher Full Text

28. Michod RE: Evolution of individuality during the transition from unicellular to multicellular life. Proc Natl Acad Sci U S A. 2007; 104(Suppl 1): 8613-8. PubMed Abstract | Publisher Full Text | Free Full Text

29. Stanley SM: An ecological theory for the sudden origin of multicellular life in the late precambrian. Proc Natl Acad Sci U S A. 1973; 70(5): 1486-9. PubMed Abstract | Publisher Full Text | Free Full Text

30. Grosberg RK, Strathmann RR: The evolution of multicellularity: A minor major transition? Annu Rev Ecol Evol Syst. 2007; 38: 621-654. Publisher Full Text

31. Kilham SS, Kreeger DA, Lynn SG, et al:: СомBO: a defined freshwater culture medium for algae and zooplankton. Hydrobiologia. 1998; 377(1-3): 147-159. Publisher Full Text

32. Herberich E, Sikorski J, Hothorn T: A robust procedure for comparing multiple means under heteroscedasticity in unbalanced designs. Plos One. 2010; 5(3): e9788.

PubMed Abstract | Publisher Full Text | Free Full Text

33. R Development Core Team R: A language and environment for statistical computing. (R Foundation for Statistical Computing, ISBN 3-900051-502 07-0, Vienna, Austria). 2011

Reference Source

34. Persson A, Hansson LA, Bronmark C, et al:: Effects of enrichment on simple aquatic food webs. Am Nat. 2001; 157(6): 654-69.

PubMed Abstract | Publisher Full Text

35. Jiang L, Joshi H, Patel SN: Predation alters relationships between biodiversity and temporal stability. Am Nat. 2009; 173(3): 389-99.

PubMed Abstract | Publisher Full Text

36. Silver PA: Synurophyte Algae. Freshwater Algae of North America: Ecology and Classification eds Wehr JD \& Sheath RG (Academic Press, New York), 2003; 523-557

Reference Source

37. Bohannan BJM, Lenski RE: The relative importance of competition and predation varies with productivity in a model community. Am Nat. 2000; 156(4): 329-340. Publisher Full Text

38. Leibold MA: A graphical model of keystone predators in food webs: Trophic regulation of abundance, incidence, and diversity patterns in communities. $A m$ Nat. 1996; 147(5): 784-812. Publisher Full Text

39. Holt RD, Grover J, Tilman D: Simple rules for interspecific dominance in system with exploitative and apparent competition. Am Nat. 1994; 144(5): 741-771. Publisher Full Text

40. Carroll SB: Chance and necessity: the evolution of morphological complexity and diversity. Nature. 2001; 409(6823): 1102-9. PubMed Abstract | Publisher Full Text

41. Boraas ME, Seale DB, Boxhorn JE: Phagotrophy by a flagellate selects for colonial prey: A possible origin of multicellularity. Evol Ecol. 1998; 12(2): 153-164.

Publisher Full Text

42. Duffy MA, Sivars-Becker L: Rapid evolution and ecological host-parasite dynamics. Ecol Lett. 2007; 10(1): 44-53.

PubMed Abstract | Publisher Full Text 


\section{Open Peer Review}

\section{Current Peer Review Status:}

\section{Version 1}

Reviewer Report 09 April 2014

https://doi.org/10.5256/f1000research.354.r4251

(c) 2014 Moya-Laraño J. This is an open access peer review report distributed under the terms of the Creative Commons Attribution License, which permits unrestricted use, distribution, and reproduction in any medium, provided the original work is properly cited.

\section{Jordi Moya-Laraño}

Functional and Evolutionary Ecology, Estación Experimental de Zonas Áridas, Almería, Spain

This article shows how increasing genetic variation in prey can stabilize the dynamics, especially since predator can barely establish in communities without variability in prey. This last finding is by far the strongest and I think that it adds substantially to a current important topic. A second relevant finding is that, despite having only a single strain with low variability, the high genetic variability replicates had also more stable dynamics than the one single strain.

The finding that colony formation was linked to predator presence and that there was a trend in which colony formation increased through time also provides a hint on how multicellularity evolved.

However, unfortunately I do not think that this article provides convincing evidence of an evolutionary response of defense through colony formation as the authors claim. First, in their preliminary assays the authors did not combine the different strains to see how they form colonies when different strains are present in the same habitat. We do not know if they are able to combine and to cooperate with other strains (at least with the information provided) and if there are emergent patterns of colony formation when more than one strain is combined.

The findings that defense (aggregative behaviour) increase when predators are present could be just the result of complex patterns of (plastic) cooperation among strains which change through time, for instance as a response to persistent predation risk. Assays at the end of the experiment to test if after removing predators, colonies were still maintained at substantially high rates (e.g. as in strain LB2405) would have been a convincing evidence for adaptive evolution ocurring during the dynamics.

Competing Interests: No competing interests were disclosed.

I confirm that I have read this submission and believe that I have an appropriate level of expertise to confirm that it is of an acceptable scientific standard. 
Reviewer Report 18 November 2013

https://doi.org/10.5256/f1000research.354.r2471

(C) 2013 Crutsinger G. This is an open access peer review report distributed under the terms of the Creative Commons Attribution License, which permits unrestricted use, distribution, and reproduction in any medium, provided the original work is properly cited.

\section{Gregory Crutsinger \\ Department of Zoology, University of British Columbia, Vancouver, BC, Canada}

The authors of this study performed a laboratory mesocosm experiment that sought to address the role of intraspecific variation in predator-prey dynamics. While the underlying questions presented an interesting and relevant avenue of research, four of the five clonal lines went extinct in their single-genotype treatment. As a result, their contrasts between low and high prey genetic diversity were performed with a single genotype (CBS strain). Consequently, it is unclear to me whether conclusions could be drawn about the consequences of genetic diversity per se, as opposed to the identity effects of this individual genotype. I agree with the authors that it is a major limitation in interpreting this experiment.

Competing Interests: No competing interests were disclosed.

I confirm that I have read this submission and believe that I have an appropriate level of expertise to confirm that it is of an acceptable scientific standard, however I have significant reservations, as outlined above.

Reviewer Report 13 February 2013

https://doi.org/10.5256/f1000research.354.r767

(C) 2013 Kisdi E. This is an open access peer review report distributed under the terms of the Creative Commons Attribution License, which permits unrestricted use, distribution, and reproduction in any medium, provided the original work is properly cited.

\section{Eva Kisdi}

Department of Mathematics and Statistics, University of Helsinki, Helsinki, Finland

This paper demonstrates that prey heterogeneity stabilizes prey population dynamics in an experimental predator-prey system. It should, however, be noted that if this happens via the betterdefended prey shunting away resources from the edible prey, then the density of the predator should be lower in the high-prey-diversity treatment. But, according to Fig 3B, this is not the case.

Competing Interests: No competing interests were disclosed.

I confirm that I have read this submission and believe that I have an appropriate level of 
expertise to confirm that it is of an acceptable scientific standard.

The benefits of publishing with F1000Research:

- Your article is published within days, with no editorial bias

- You can publish traditional articles, null/negative results, case reports, data notes and more

- The peer review process is transparent and collaborative

- Your article is indexed in PubMed after passing peer review

- Dedicated customer support at every stage

For pre-submission enquiries, contact research@f1000.com 